\title{
Justification of the Optimal Granulometric Composition of Crushed Rocks for Open- Pit Mine Road Surfacing
}

\author{
Viktor Shalamanov ${ }^{1, *}$, Vladimir Pershin ${ }^{1}$, Serguey Shabaev ${ }^{1}$, Dmitry Boiko ${ }^{1}$ \\ ${ }^{1}$ T.F. Gorbachev Kuzbass State Technical University, Mining Institute, 650000, Kemerovo, Russia
}

\begin{abstract}
The specific weight of the open coal mining method in Kuzbass is constantly growing due to higher hazard and low profitability of the underground mining method. It is possible to reduce the cost of open-pit coal mining using overburden rock in constructing temporary pit roads. The purpose of the work is to justify the possibility of using overburden rock for the construction of temporary technological roads. To this end, we set the tasks to determine the rational granulometric composition of crushed rock, dependences of its unit weight, static elastic modulus, and ultimate shear resistance. This study justifies the most efficient granulometric composition of crushed rock based on theoretical studies of the optimal structure of granular materials, taking into account the probability theory of particle-particle packing, laboratory studies of the dependence of the unit weight and the static elastic modulus on the content of particles of different sizes, and also the calculation of ultimate shear resistance of crushed rocks. As a result of the conducted studies, it has been established that the optimal granulometric composition of crushed rock, which at the same time ensures high values of unit weight, static elastic modulus and ultimate shear resistance, is achieved when the content of particles larger than half of the maximum is 40 to $55 \%$ and increases integrally with decreasing of the average particle diameter.
\end{abstract}

\section{Introduction}

Road surface is one of the most important elements of the pit road dressing, the average speed of pit transport and, consequently, its efficiency largely depend on the condition of roads. Taking into account that transportation costs make up 40 to $70 \%$ of total costs, improving the quality of road topping is one of the main ways to reduce the cost of mineral mining by the open-cast method.

The experience of coal mines operation in Kuzbass has shown that construction of asphaltconcrete and cement-concrete pavements is not justified economically when it comes to roads in a dynamically developing quarry space, where temporary roads make up to $80 \%$ of their total length. The most suitable for construction of road dresses of both permanent and temporary technological roads is crushed rock.

\footnotetext{
*Corresponding author: shalamanov49@mail.ru
} 
The analysis of previous studies [1-11] shows that the crushed rock of the optimal granulometric composition should consist of various size particles taken in a certain quantitative ratio, which provides increased internal friction and adhesion between the particles, high unit weight and an insignificant intensity of the grain grinding process [12 - 15]. These conditions can be achieved with the largest possible number of coarse particles and minimal content of fine and silty particles necessary to create high unit weight and to ensure the cohesion of large particles.

\section{Materials and methods}

These conclusions which take into account the main theoretical provisions of A.V. Biryukov, B.S. Radovsky, and I.I. Kandaurov, were laid in the basis of the theoretical model of optimal packing of different-sized particles, the following assumptions and conjectures were introduced in it:

The entire crushed rock consists of N-components, and a certain fraction characterized by an average diameter is taken as a component. It is inconvenient to use the absolute values of the average diameters of the particles, so in the theoretical model, the average particle diameters of a certain fraction were replaced by relative dimensions, such as Dmax, Dmax / 2, Dmax / 4, and so on. The particles of the largest component are evenly distributed throughout the volume, which allows us to consider not the entire set of particles (a macro object), but only one of them (a discrete object). All particles have the shape of a sphere. If we take the shape of the particles in the form of a cube, then theoretically the minimum voidness of a layer arranged from such a fragmented rock will tend to porosity of the rock itself, since individual particles can closely touch each other on all sides. It is difficult to consider a form in the form of a tetrahedron using random packing of particles, since grains can occupy one position, but they always have a different orientation in space. But the shape of particles in the form of a sphere satisfies both conditions: between particles there is always space (voids) that cannot be completely filled; regardless of the location of an individual particle, its orientation in space doesn't affect the package. To test the adequacy of the theoretical model, a laboratory study was made of the dependences of the unit weight and the static modulus of elasticity of crushed rocks of different granulometric composition. In addition, the ultimate shear resistance of that crushed rock was calculated.

All laboratory studies were performed on samples of crushed rock of different granulometric composition presented in Table 1.

Table 1. Selected grain size distributions of crushed rock

\begin{tabular}{|c|c|c|c|c|c|c|}
\hline \multirow{2}{*}{ Blend \# } & \multicolumn{7}{|c|}{ Full residue, \%, on sieves, mm: } \\
\cline { 2 - 7 } & $\mathbf{1 0}$ & $\mathbf{5}$ & $\mathbf{2 . 5}$ & $\mathbf{0 . 6 3}$ & $\mathbf{0 . 1 6}$ & $\mathbf{0 . 0 5}$ \\
\hline$\# 1$ & 9.70 & 24.09 & 33.08 & 48.91 & 56.64 & 71.83 \\
\hline$\# 2$ & 12.93 & 28.91 & 46.90 & 55.70 & 66.86 & 77.47 \\
\hline$\# 3$ & 33.95 & 48.33 & 61.82 & 61.82 & 81.14 & 85.48 \\
\hline$\# 4$ & 48.50 & 58.09 & 62.58 & 66.54 & 69.63 & 80.92 \\
\hline$\# 5$ & 29.10 & 43.48 & 61.47 & 69.39 & 77.11 & 83.63 \\
\hline$\# 6$ & 19.40 & 38.58 & 52.07 & 67.90 & 79.49 & 83.83 \\
\hline$\# 7$ & 38.80 & 57.98 & 66.97 & 66.97 & 86.29 & 88.46 \\
\hline$\# 8$ & 58.19 & 72.58 & 81.57 & 89.49 & 93.35 & 93.35 \\
\hline$\# 9$ & 48.50 & 58.09 & 67.08 & 75.00 & 78.86 & 85.37 \\
\hline$\# 10$ & 58.19 & 67.79 & 76.78 & 80.74 & 83.06 & 88.26 \\
\hline
\end{tabular}




\section{Results}

The proposed theoretical model was implemented by means of computer simulation. The simulation results are shown in Table 2.

Table 2. Optimal grain size distribution of crushed rock based on theoretical studies

\begin{tabular}{|c|c|c|c|c|c|c|c|c|c|c|c|c|c|c|}
\hline $\begin{array}{c}\text { Component dia., } \\
\text { mm }\end{array}$ & हี้ & 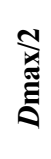 & 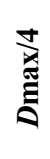 & 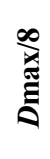 & 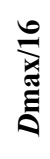 & ֶֶ. & 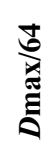 & 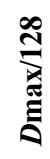 & 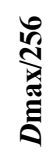 & 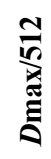 & 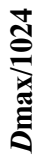 & & 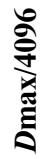 & 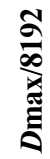 \\
\hline \begin{tabular}{|c|} 
The total content \\
of the components \\
(total residue), $\%$ \\
by volume \\
\end{tabular} & $\stackrel{\nabla}{i}$ & $\begin{array}{l}2 \\
\hat{\infty} \\
n\end{array}$ & $\begin{array}{l}\infty \\
0 \\
\dot{0}\end{array}$ & $\stackrel{?}{\stackrel{7}{\pi}}$ & $\hat{\grave{T}}$ & $\stackrel{i}{i}$ & $\begin{array}{l}8 \\
\stackrel{\infty}{\infty}\end{array}$ & $\underset{\infty}{\tilde{\infty}}$ & $\stackrel{2}{\stackrel{0}{\infty}}$ & $\underset{\infty}{\infty}$ & $\begin{array}{l}\bar{b} \\
\dot{\infty}\end{array}$ & ố & $\overrightarrow{\tilde{i}}$ & $\begin{array}{l}\hat{\sigma} \\
\text { à }\end{array}$ \\
\hline
\end{tabular}

The obtained results made it possible to determine the theoretical dependence characterizing the optimal granulometric composition of the crushed rocks:

$$
V_{D}=52.4+\int_{D}^{0.5 D \max }\left(\frac{\frac{30}{(D \max +25)^{0.5}}+1.84}{D^{0.8}}\right) d D,
$$

where $V_{D}$ - total content by volume of the $\mathrm{i}$-th component and all the previous larger components, $\% ; D$-average diameter of particles of the $i$-th component, $\mathrm{mm} ; D_{\max }$ - average diameter of particles of the largest component, $\mathrm{mm}$.

The results of the laboratory tests are shown in Figures 1 and 2 with reference to crushed rock rocks of coarse-grained sandstone with the maximum grainsize $D_{\max }=20 \mathrm{~mm}$.

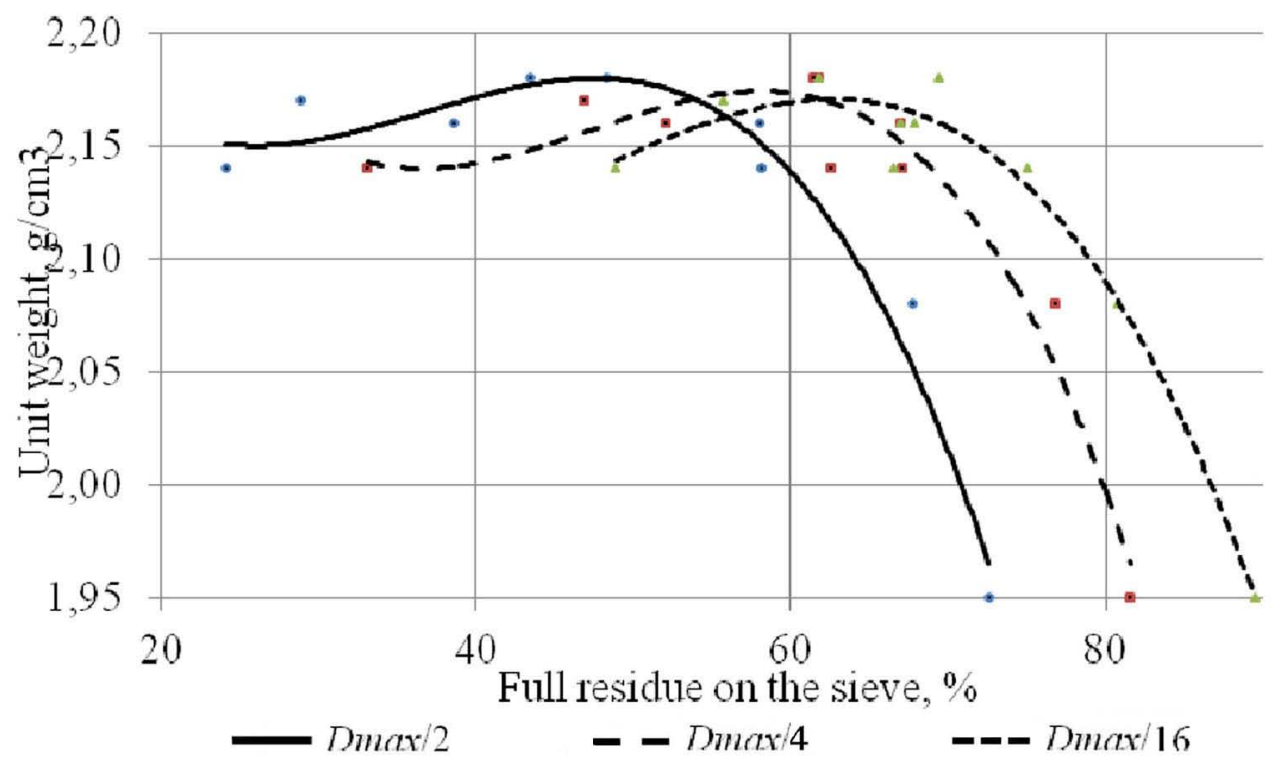

Fig.1. Dependences of unit weight on full residue of the sieves of a given size 


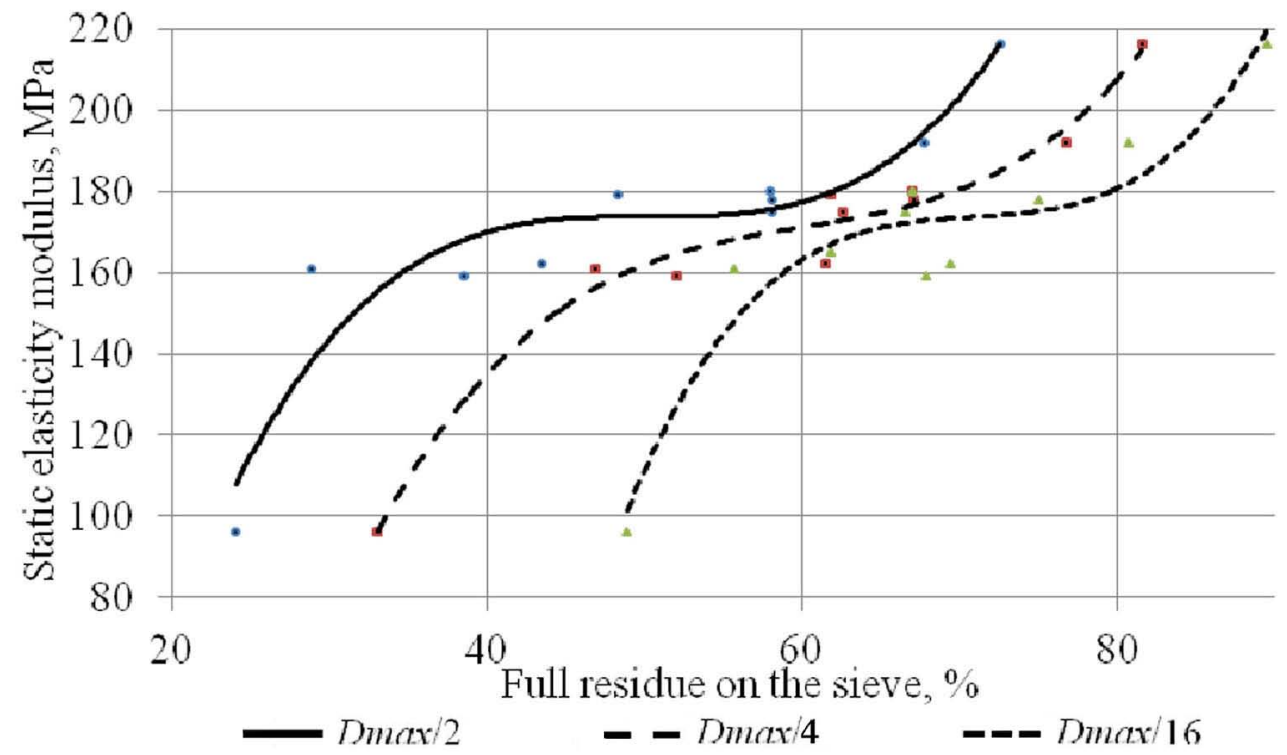

Fig. 2. Dependences of elasticity modulus on full residue on the sieves of a given size

The response functions of the unit weight $(\rho)$ and the static modulus of elasticity (E) of the crushed rocks from the total residue on the sieve of a given size have the form (the values of the coefficients of the regression equations are given in Table 3):

$$
\begin{aligned}
& \rho\left(V_{D}\right)=0,79 \cdot \rho_{0} \cdot\left[\cos \left(\frac{V_{D}^{2}-k_{1}}{k_{2}}\right)\right]^{2}, \\
& E\left(V_{D}\right)=\int_{0}^{V_{D}} k_{3} \cdot V_{D}^{k_{4}} \cdot\left[1-\cos \left(k_{5} \cdot V_{D}\right)\right]^{k_{6}} d V_{D}+40,
\end{aligned}
$$

where $V_{D}$ - content of particles over $D \mathrm{~mm}$ in size in the crushed rock, $\% ; \rho_{0}-$ density of the initial rock mass, $\mathrm{g} / \mathrm{cm}^{3} ; k_{1}, k_{2}, k_{3}, k_{4}, k_{5}, k_{6}$ - coefficients of regression equations.

\begin{tabular}{|c|c|c|c|c|c|c|}
\hline \multirow{2}{*}{$\begin{array}{l}\text { Average } \\
\text { diameter }\end{array}$} & \multicolumn{6}{|c|}{ Regression equation coefficient value } \\
\hline & $k_{1}$ & $k_{2}$ & $k_{3}$ & $\boldsymbol{k}_{4}$ & $k_{5}$ & $k_{6}$ \\
\hline$D \max / 2$ & 800 & 9000 & 13.5 & -0.537 & 0.091 & 0.721 \\
\hline$D \max / 4$ & 1800 & 10000 & 0.838 & 0.223 & 0.075 & 0.822 \\
\hline$D \max / 8$ & 2800 & 13000 & 0.032 & 1.06 & 0.070 & 0.700 \\
\hline$D \max / 16$ & 3200 & 14000 & 0.0028 & 1.60 & 0.060 & 0.600 \\
\hline
\end{tabular}

Table 3. Coefficients of regression equations

The DalNII has developed a technique for estimating the strength characteristics (ultimate shear resistance) for coarse clastic soils, which in fact differ little from fractured rocks. It is based on the dependence of the angle of internal friction and the specific cohesion of crushed rocks on the content of particles (debris) having a size of more than $2 \mathrm{~mm}$. Further, according to the Coulomb law, the ultimate shear resistance is calculated. Graphical representation of the results of the performed calculation is shown in Figure 3. 


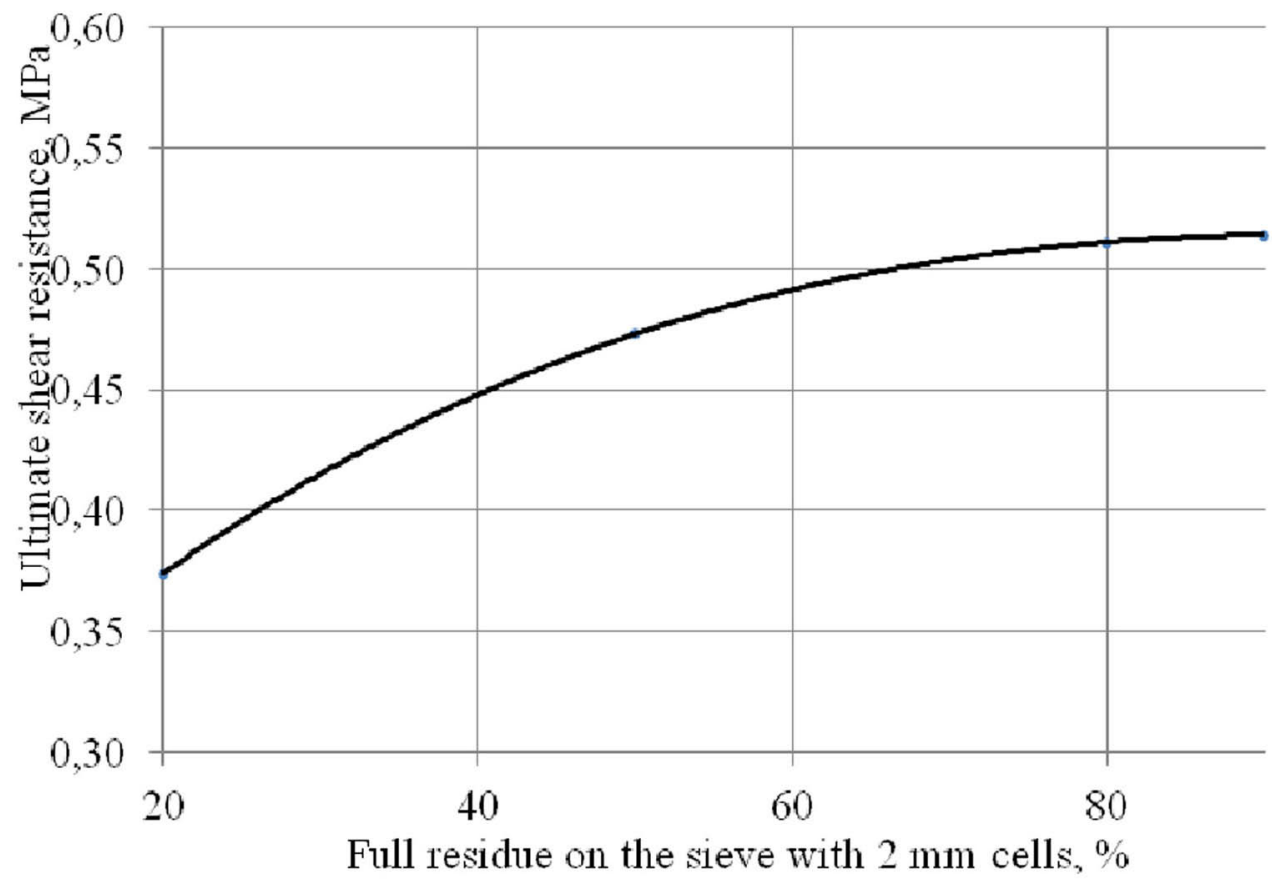

Fig. 3. Dependence of the ultimate shear resistance of crushed rocks on the content of particles over 2 $\mathrm{mm}$ in their composition

The obtained dependences of the volumetric mass, the static elastic modulus and the ultimate shear limiting resistance of the crushed rocks on their granulometric composition made it possible to optimize it.

Comparison of empirical data with the results of theoretical studies shows that they almost completely coincide. The difference is that according to the results of the experimental data, the optimum particle size distribution represents a region, and in theoretical studies, it is the only value in this optimal region. Consequently, the dependence characterizing the optimal granulometric composition of crushed rocks can be written in the form:

$$
V_{D}=(40 \ldots 55)+\int_{D}^{0.5 D \max }\left(\frac{\frac{30}{(D \max +25)^{0.5}}+1.84}{D^{0.8}}\right) d D
$$

\section{Conclusions}

The optimal granulometric composition of the crushed rock, which at the same time ensures high values of unit weight, static elastic modulus and ultimate shear resistance, is achieved when the content of particles larger than half of the maximum is 40 to $55 \%$ and integrally increases with a decrease in the average particle diameter.

\section{References}

1. Czermak V, Huckenholz HG, Rybach L, et al., Physical properties of rocks (1982)

2. Monicard RP., Properties of reservoir rocks: core analysis (1980)

3. Bucher, Kurt, Grapes, Rodney, Petrogenesis of metamorphic rocks (2011) 
4. Farmer IW (Ed.), Engineering behaviour of rocks (1983)

5. LianYing Zhang, XianBiao Mao, AiHong Lu., Science in China Series E: Technological Sciences, 52, 641 (2009)

6. A. K1lic, A. Teymen., Bulletin of Engineering Geology and the Environment, 67, 237 (2008)

7. P. Hartlieb, M. Toifl, F. Kuchar et al., Minerals Engineering. 91, 34 (2016)

8. Chandong Chang, Mark D. Zoback, Abbas Khaksar, Journal of Petroleum Science and Engineering, 51:3-4, 223 (2006)

9. Gioacchino Francesco Andriani, Mario Parise, Journal of Rock Mechanics and Geotechnical Engineering, 19 (2017)

10. Mohammadreza Hemmati Nourani, Mohsen Taheri Moghadder, Mohsen Safari, Journal of Rock Mechanics and Geotechnical Engineering, 8 (2016)

11. Jonny Rutqvist, Antonio P. Rinaldi, Frederic Cappa et al., Journal of Rock Mechanics and Geotechnical Engineering, 8:6, 789 (2016)

12. Zong-Xian Zhang, Journal of Rock Mechanics and Geotechnical Engineering, 8:6, 886 (2016)

13. Yaodong Jiang, Yixin Zhao, Hongwei Wang et al, Journal of Rock Mechanics and Geotechnical Engineering, 24 (2016)

14. L. Dormieux, E. Lemarchand, D. Kondo et al., Journal of Rock Mechanics and Geotechnical Engineering, 20 (2017)

15. Askeri Karakus, Mahmut Akatay, Nondestructive Testing and Evaluation, 28:4, 342 (2013) 